\title{
A UNIVERSIDADE EM REGIÕES AMAZÔNICAS: pesquisa, ensino e mudança social
}

Lucio Jose Dutra Lord

\section{Resumo}

A universidade tem seu papel discutido na atualidade e demandas diversas lhe são dirigidas, gerando desafios para sua consolidação como ator social. No caso da região amazônica os desafios são envoltos por dinâmicas sociais pautadas pela desigualdade, históricos de silenciamentos e discursos legitimadores do exercício do poder. O presente artigo discute esses temas a partir da investigação sobre o papel que a Universidade do Estado do Mato Grosso desenvolveu entre 2006 e 2019 na região da Amazônia matogrossense por meio de programas de pesquisa e projetos de ensino engajados com a realidade de grupos menos favorecidos. O estudo é de base sociológica e dialoga com perspectivas da análise do discurso e da educação. Como resultado conclui-se que o papel e atuação da Universidade depende de condições internas e externas, exigindo análise de conjuntura.

Palavras-chave: universidade; Amazônia, discurso; poder.

\section{THE UNIVERSITY IN AMAZON REGIONS:}

\author{
research, teaching and social change
}

\begin{abstract}
The university's work is currently discussed and demands are made on them, creating challenges for their political actions in society. In the Amazon region, the challenges are greater because there is more inequality, processes of silence and speeches of power and violence. This article discusses these themes and investigates the activity that the State University of Mato Grosso developed between 2006 and 2019 in the Amazon region of Mato Grosso through research programs and teaching projects carried out in the reality of poor social groups. The study is sociological and establishes exchanges with perspectives on discourse analysis and education. The conclusion is that the University's action depends on internal and external conditions.
\end{abstract}

Keywords: university; Amazon, discourse; power.

\section{LA UNIVERSIDAD EN REGIONES AMAZÓNICAS: investigación, docencia y cambio social}

\section{Resumen}

Actualmente se discute el trabajo de la universidad y se les exige, creando desafíos para sus acciones políticas en la sociedad. En la región amazónica, los desafíos son mayores porque hay más desigualdad, procesos de silencio y discursos de poder y violencia. Este artículo analiza estos temas e investiga la actividad que la Universidad Estatal de Mato Grosso desarrolló entre 2006 y 2019 en la región amazónica de Mato Grosso a través de programas de investigación y proyectos de enseñanza llevados a cabo en la realidad de los grupos sociales pobres. El estudio es sociológico y establece intercambios con perspectivas sobre el análisis del discurso y la educación. La conclusión es que el papel y el desempeño de la universidad dependen de las condiciones internas y externas.

Palabras clave: universidad; Amazonas, discurso; poder. 


\section{INTRODUÇÃO}

Se tomado o conhecimento numa perspectiva libertadora, então qual é o papel da Universidade em sociedades marcadas pelas violências física e simbólica como é o caso da região da Amazônia mato-grossense? E nesse contexto seria a Universidade um espaço possível para a construção de verdades questionadoras das relações poder / saber e dos processos de silenciamentos que operam sobre as minorias sociais? Ou, como pode a Universidade desempenhar papel de ator político na mudança do imaginário coletivo, alterando noções de direito e de justiça social?

Essas questões têm composto a agenda de discussões sobre o papel das universidades na atualidade brasileira. Diante disso, o objetivo do presente artigo é contribuir para responder as questões acima apresentadas, a partir de análises das ações desenvolvidas especificamente pela Universidade do Estado do Mato Grosso na região Norte do estado, área da Amazônia Legal. O material em estudo é composto por investigações e dados diversos já levantados pelo Programa de Pesquisa em Sociologia, desenvolvido entre 2006 e 2019 na Faculdade de Educação e Linguagem da respectiva Universidade, cujo objetivo geral foi compreender os processos de formação das sociedades na Amazônia mato-grossense. As análises aqui desenvolvidas e as conclusões propostas são inéditas em relação àqueles estudos porque, neste artigo, a preocupação é refletir sobre o papel que a Universidade desempenhou no processo de construção de conhecimentos e resgate de outras histórias acerca daquela região, se opondo aos discursos de poder. É com base nessa reflexão que se busca responder sobre o papel que a Universidade tem a desenvolver na contracorrente dos processos de dominação e como resistência e (re)criação de significados que, quando socialmente difundidos, podem colocar em cheque a ordem social desigual estabelecida em nível local e que está intrinsecamente ligada às desigualdades sociais do país.

\section{A METODOLOGIA DO ESTUDO}

A metodologia empregada para este artigo teve como principal abordagem o estudo de caso, acompanhado pela revisão bibliográfica, já que os estudos desenvolvidos no âmbito do Programa de Pesquisa em Sociologia são aqui revisitados e alinhados pelo esforço de identificar o papel que a Universidade desempenhou na construção de discursos diferentes daqueles até então produzidos pelo processo de formação da sociedade local. Contudo, é salutar identificar distanciamentos entre o que foi produzido pelo Programa e o que, de fato, é analisado no presente artigo. Isto porque o objetivo dos textos, artigos, livros e relatórios do Programa era fazer conhecer uma história diferente acerca da formação das sociedades na Amazônia matogrossense e distanciar-se do discurso até então dominante e disseminado pelo senso comum na população. Por sua vez, o que interessa ao presente artigo é refletir sobre o papel que a Universidade desempenhou quando assumiu o desafio de reconstruir narrativas sobre a formação daquelas sociedades durante o desenvolvimento do Programa. Noutras palavras, a revisão teórica desenvolvida neste artigo não se limita a retomar aspectos já apresentados em textos anteriores, mas acende possibilidades de repensar o produzido, transitar entre os conhecimentos já construídos e, a partir desses, lançar um novo olhar, uma nova compreensão que implica produzir novo conhecimento, como propuseram Frodeman, Klein e Pacheco (2017).

Para além do que está materializado em publicações, o presente artigo também utiliza como dados as produções dos discentes envolvidos no Programa, tais como relatórios e artigos finais apresentados como atividades avaliativas em disciplinas da matriz curricular. A consulta a 
esse material se dá pelo acesso ao que chamam de nuvem, uma vez que foram armazenados inicialmente em disco, seguindo para drive online convertido em nuvem passível de compartilhamento entre docentes e discentes. Ainda, somam-se ao material analisado os diários de classe e anotações realizadas pelos docentes no sistema institucional de registro das atividades acadêmicas. Esses são acessíveis pelo Sistema Acadêmico (SAGU) ${ }^{1}$ que armazena informações de todas as disciplinas na Universidade desde 2008, com caráter obrigatório e semestral.

Para a elaboração do presente artigo foram consultados 40 trabalhos discentes de graduação, realizados entre os anos de 2010 e 2018 no município de Sinop, divididos em: 10 relatórios de pesquisa realizadas no bairro operário Maria Carolina; 10 relatórios de pesquisa realizadas no bairro operário Jardim do Ouro; 18 artigos sobre as cidades de Sinop, Itaúba, Peixoto de Azevedo, Matupá e Guarantã do Norte, situadas na Amazônia legal mato-grossense; e duas exposições fotográficas sobre a região. No que se refere à produção de discentes de mestrado foram selecionados 10 trabalhos, todos em formato de relatórios sobre pesquisa de campo, realizada em 2019, no bairro operário Jardim do Ouro, em Sinop. Já nos registros acadêmicos das disciplinas de Sociologia Geral e Urbana, Sociologia do Trabalho e Sociologia, ofertadas aos cursos de Engenharias, foram consultados os semestres letivos de 2013/2, 2014/1, 2015/1, 2016/1, 2017/1, 2018/1, quando verificaram-se as atividades desenvolvidas de pesquisa de campo e de produção de materiais escritos ou imagens; anotações docentes de planejamento; objetivos da proposta; seus resultados; bem como limites enfrentados.

Do conjunto desses dados seguiu-se a elaboração do presente artigo, orientado pela escolha teórico-referencial no campo da Sociologia. Acerca desta cabe retomar a fala de Bourdieu (2002, p. 26) para quem a investigação sociológica permite adotar diversos recursos “[...] entre os vários que podem ser oferecidos pelo conjunto das tradições intelectuais da disciplina”. Assim, do longo percurso desenvolvido pela Sociologia no século XX, abre-se a permissão para realizar o que Nunes (1978) chamou de "aventura sociológica" - a capacidade da disciplina em transitar por metodologias e referenciais teóricos e utilizá-los na medida e nos momentos em que puderem desempenhar papel instrumental na construção do conhecimento, desobrigada a filiação a uma ou outra corrente de modo restritivo e limitador. Contudo, as palavras que deram início a este artigo já apontaram para uma extrapolação do campo da Sociologia, mediante o diálogo com a disciplina de Análise do Discurso, especialmente quanto à adoção de conceitos desenvolvidos por Orlandi (1999; 2015) e Foucault (1996; 2015). Mas, mesmo esse diálogo é construtivo para um fazer científico que visa romper com as amarras colocadas pela disciplinaridade e se soma a uma nova epistemologia, como propõe Santos (1988).

\section{A ESCOLHA POR ANALISAR OS DISCURSOS}

Análises sobre os processos de dominação são comuns na Sociologia, fazendo parte das preocupações de seus primeiros pensadores. No Brasil, essa característica foi acentuada com a Escola de Sociologia da USP, impulsionada por estudos como os desenvolvidos por Fernandes (1972), Cardoso (1970), Ribeiro (2006) e outros. Há uma característica nessa Sociologia brasileira que é o esforço por reconstruir a história da sociedade brasileira, desvinculando-se de consensos impostos pelas elites, que silenciaram o papel das minorias sociais, para criar a falsa visão de que a escravidão de negros e o genocídio de indígenas foi algo brando.

Nas análises sociológicas brasileiras sobre o país, o conceito de dominação foi muitas vezes atrelado ao de ideologia, seguindo a proposta desenvolvida por Marx e Engels (2007) mas

\footnotetext{
${ }^{1}$ O Sistema é acessado pela comunidade universitária em http://academico.unemat.br/
} 
adaptada para uma sociedade de industrialização tardia, o que contribuiu para a construção da teoria da dependência. Ocorre que esses conceitos, junto ao de dependência e suas implicações, também desenham o pano de fundo dos estudos em Análise do Discurso, uma disciplina nova em comparação à Sociologia como ciência, mas que com ela mantém muitas afinidades. De modo resumido e aqui simplista, porque não é o centro da discussão do artigo, pode ser estabelecido um conjunto de aproximações, trocas e mútua-influência entre as análises sociológicas e as linguísticas. Esse é o caso de Cândido (2006) que discutiu os impactos da expansão urbana sobre o caipira no interior do país, na década de 1940. Mas também ocorreu algo semelhante na França de Michel Pêcheux e de Michel Foucault entre as décadas de 1960 a 1980, permitindo aos conceitos um trânsito entre as disciplinas, sem perda do rigor teórico-metodológico. Assim, a ideologia - como representação socialmente construída por uma elite dominante e imposta à coletividade, e que não condiz necessariamente com a realidade social, mas que tem como função conduzir um entendimento que beneficia e legitima o grupo no poder, como definiu Chauí (2004) - compôs a base da crítica sociológica e também da Análise do Discurso. Desse modo, o discurso torna-se objeto de investigação de diversas abordagens teóricas, permitindo o percurso neste artigo entre Sociologia e Análise do Discurso.

Mas o que há no discurso ou nos discursos que tanto pode interessar às análises sobre a sociedade? Foucault (1996) fez um questionamento muito semelhante, ao qual respondeu afirmando que um discurso opera como parte de uma estrutura de poder, historicamente construída, na qual os sujeitos são legitimados ou silenciados, a depender se desempenham papéis de interesse à perpetuação das relações de dominação e de controle social. No Brasil, os estudos de Orlandi (2015) desenvolveram com mais afinco a noção de que os silenciamentos se dão não só pela proibição de outros discursos, mas também pela alteração ou deslocamento de sentidos. Nessa perspectiva, os significados são alterados pela relação entre espaço e tempo, por processos nos quais a história seleciona determinados eventos e faz esquecer outros, atribuindo novos significados que, com o tempo, são desvinculados daqueles iniciais, permitindo a manipulação dos sentidos (ORLANDI, 1999).

$\mathrm{Na}$ medida em que os significados dos discursos são alterados e lhes são atribuídas representações que condizem com a ordem dominante imposta à sociedade, eles acabam por atuar como parte do exercício de poder que, a depender da perspectiva teórica adotada, condiz com o conceito de violência simbólica, tal como elaborado por Bourdieu (2007). Essa violência opera por espaços, procedimentos, rituais e narrativas em que a realidade das minorias sociais é desconsiderada, suas falas são deslegitimadas e seus papéis na sociedade ignorados. Sobre eles, o discurso dominante é colocado e o silenciamento imposto. Aplicada ao caso da Amazônia matogrossense, a história contada para as novas gerações é resultado da seleção de eventos e da manipulação de seus significados, o que produz um imaginário coletivo que não permite a compreensão da realidade social vivida. Mais ainda, o resultado são personagens desprovidos de empoderamento, limitados ou incapacitados para desempenhar papel de atores políticos na sociedade em que vivem. Daí que o discurso, em seus princípios e procedimentos, constitui objeto relevante às análises sociais, como ensinou Orlandi (2015).

\section{O CONTEXTO DA REGIÃO EM ANÁLISE E A CONSTRUÇÃO DE UM DISCURSO}

Na década de 1970 ocorreu o processo de colonização da Amazônia Mato-grossense que, desde os anos 1930, fazia parte de projetos do governo federal (GUIMARÃES NETO, 2002). Assim, as cidades resultantes desse processo têm, hoje, mais de quatro décadas, registrando três ou mais gerações de famílias que experienciam trabalhar e viver na região. Do processo cotidiano 
e das relações sociais estabelecidas ao longo do período resultaram representações sociais sobre quem são suas gentes, sobre a divisão social dos bens, direitos e poderes, assim como compreensões de si e dos outros, em especial dos outros que de lá foram retirados pela criação das cidades - os indígenas. Noutras palavras, a dinâmica social desenvolvida localmente arquitetou modos de divisão de acesso aos bens sociais, em especial à terra urbana e rural, legitimando o que seriam os direitos de uns, em detrimento da maior parte da população.

Inicialmente marcada por violência, grilagem e assassinatos (OLIVEIRA, 1997), no decorrer do tempo a história da colonização incorporou outros sentidos, transitando para a valorização do processo de ocupação e comércio de terras e a criação de personagens conhecidos como "pioneiros". Esses personagens pioneiros tiveram seus nomes registrados em avenidas, bairros, praças e escolas, algo que ocorreu concomitante à valorização de narrativas acerca do homem sulista, que teria vencido os desafios da natureza amazônica (SOUZA, OLIVEIRA, STRAUB, 2015). Na prática, esse discurso recolocou a narrativa de superioridade da cor branca em relação às populações pardas tradicionais e indígenas originais do local. A história ensinada nas escolas sobrevalorizou os papéis e ações que famílias pioneiras teriam realizado para a existência daquelas cidades (LORD, 2011). Imortalizados seus nomes em espaços públicos, a ideia de pessoas e famílias pioneiras acabou por contribuir com a legitimidade da distribuição desigual e concentração das riquezas na região (SILVA, BAMPI, 2019).

Contudo, o mesmo discurso e práticas que valorizaram o chamado "pioneirismo" de alguns indivíduos, acabaram por silenciar a história de grupos populacionais inteiros, em especial de indígenas e de migrantes de origem do Norte e Nordeste do país (TOME, ROHDEN, 2017). Hoje, a região apresenta características urbanas de delimitações visíveis entre os chamados bairros tradicionais e bairros populares, apartados por avenidas e rodovias, com acesso diferente aos serviços públicos e à infraestrutura urbana. $\mathrm{E}$ as zonas rurais apresentam, como características, a concentração de terras e de tecnologias do agronegócio, em oposição à redução gradual da agricultura familiar (CELLA-SILVA, TOME, 2019).

As cidades da região, com destaque para a cidade de Sinop, têm mantido o controle sobre a formação populacional mediante a valorização (ou especulação) do solo urbano. Em regra, a urbanização se expande sobre as áreas rurais mais próximas, viabilizando economicamente a abertura de novos loteamentos / bairros para o comércio de terrenos para moradia. Destacam-se, nesse processo, empresas imobiliárias que, desde os projetos pilotos das cidades nos anos de 1970, adquiriram as áreas. Além dessas, novos grupos imobiliários de famílias que enriqueceram no local, fosse pelo comércio, pelo agronegócio ou pela política, somam-se à atividade de comércio de terrenos urbanos. Uma vez que a expansão urbana é dirigida por grupos econômicos e famílias claramente identificáveis, essas controlam os valores imobiliários e assim selecionam, pela renda e escolaridade, as famílias que ingressam nos municípios. Por sua vez, os órgãos públicos buscam inibir as sub-habitações e ocupações irregulares do solo urbano, o que ajuda para que as cidades se estendam no limite dos projetos imobiliários e os valores cobrados sejam mantidos. Assim, o modo de funcionamento da cidade é antidemocrático e legitima as desigualdades sociais por meio de práticas acompanhadas de discursos ${ }^{2}$.

Há no conjunto desses empreendimentos imobiliários as propagandas que disseminam narrativas de cidades planejadas, ricas, resultantes do sucesso do trabalho de famílias pioneiras que teriam desbravado a Amazônia. Mas tal discurso ocorre junto ao cenário de especulação do

\footnotetext{
${ }^{2}$ Essas análises estão presentes nos relatórios da disciplina de Discurso e Texto ofertada no Mestrado em Letras da Universidade do Estado do Mato Grosso, campus de Sinop. Há relatórios publicados em modelo de paper, cujo resumos estão disponíveis nos sites dos eventos científicos locais: http://www.conaell.com.br/ e https://eventos.faepenmt.com.br/evento/ix-enaed-encontro-anual-de-educacao.
} 
custo dos terrenos urbanos que, por sua vez, acompanha a elevação do valor das terras de produção agrícola que se concentram também em grupos econômicos - com crescente participação de capital estrangeiro (SOUZA, 2013).

Desse processo de concentração de áreas urbanas e rurais resulta a manipulação dos valores da terra, o que traz como consequência a exclusão social daqueles que não conseguem adquirir uma parcela do solo para moradia. Além disso, o alto custo do solo urbano e rural gera um bloqueio para aqueles que migram em busca de emprego, saúde e educação. Tal contexto se torna ainda mais excludente, porque as cidades menores do entorno experimentaram, na última década, a diminuição de suas populações em função do desemprego estrutural e pela redução da agricultura familiar, trazidos pelo modelo produtivo do agronegócio. Desse modo, o discurso de pioneirismo ocorre juntamente com a busca por legitimar a concentração das terras, de riquezas e de poderes nas cidades da região. E é nesse mesmo contexto que deve ser questionado o papel da Universidade, quando compreendida como espaço de produção de conhecimentos.

Ocorre, ainda, que as representações sociais desempenham papel relevante a partir do qual as dinâmicas sociais se dão. Compreendido isso, ou não, fato é que as empresas colonizadoras que criaram as cidades na região amazônica mato-grossense desempenharam papel central na construção dos discursos e representações sobre a vida local. Desde os primeiros anos com o comércio de terras e a ideia do novo el dorado, até o ano de 2020, com a abertura de novos loteamentos particulares de terrenos para comércio, se mantêm constantes as construções discursivas das empresas colonizadoras e dos grupos imobiliários sobre o que é uma cidade, sua história, seu presente e futuro. E por essas construções narrativas, reiteradas e acompanhadas de ações que configuram o conceito de discurso (ORLANDI, 1999; FOUCAULT, 1996), a noção de verdade é imposta aos diversos grupos sociais que compõem a população urbana e rural da região. Essa verdade é silenciadora de outras tantas verdades, do mesmo modo que o discurso silencia outras narrativas.

\section{O PROGRAMA DE PESQUISA E A IDENTIFICAÇÃo DE OUTROS DisCURSOS POSSÍVEIS}

Entre 2006 e 2019, a Universidade do Estado do Mato Grosso desenvolveu o Programa de Pesquisa em Sociologia, com o objetivo de tornar conhecido o processo de colonização na região da Amazônia mato-grossense, em especial aquele decorrente da criação de cidades ao longo da Rodovia BR163, entre as cidades de Sinop, Itaúba, Peixoto de Azevedo, Matupá e Guarantã do Norte - todas dentro da região da Amazônia legal. O Programa foi composto por projetos de pesquisa que, seguindo o objetivo geral, buscaram fazer emergir outros entendimentos sobre a colonização da região, em especial, entendimentos diferentes daqueles disseminados por empresas privadas que atuaram na criação das cidades e que ainda detêm a maior parte das terras, com alto valor imobiliário na Amazônia mato-grossense. Como produtos, as pesquisas propuseram a publicação de textos e a realização de eventos de caráter científico e extensionista, tanto para a divulgação e debate de dados e análises junto à comunidade acadêmica e gestores públicos locais, como para a formação continuada de profissionais de escolas públicas de educação básica local.

Mas, no âmbito do Programa também foram desenvolvidos projetos socioeducativos e realizadas práticas pedagógicas ${ }^{3}$. O princípio orientador que justificou a adoção das práticas pedagógicas foi o de que compreender criticamente o espaço social e suas dinâmicas constitui

\footnotetext{
${ }^{3}$ Como práticas pedagógicas são compreendidas aquelas atividades que têm função de formação discente, seguindo o
} estabelecido pela Resolução n. 02/2019 do Conselho Nacional de Educação, de 20 de dezembro de 2019. 
passo fundamental para que o profissional possa intervir na realidade e constituir-se como cidadão, seguindo a proposta em curso, no período, do Plano Nacional de Educação e, agora, na Base Nacional Comum Curricular. A partir de quatro disciplinas principais foram desenvolvidas atividades de pesquisa de campo, com coleta de dados por entrevistas domiciliares, documentação de narrativas de história de vida, registro de imagens e diários de campo que convergiram em relatórios e exposição de trabalhos escritos, orais e exposições fotográficas. As disciplinas foram Sociologia Geral e Urbana e Sociologia do Trabalho, ofertadas nos cursos de bacharelado em Engenharia Civil e Engenharia Elétrica; Sociologia ofertada para os diversos cursos de Licenciatura; e a disciplina de Discurso e Texto ofertada no Programa de Mestrado Acadêmico em Letras. Nelas foram propostas atividades que permitiram aos estudantes experiências de metodologia de pesquisa etnográfica, articuladas com reflexões teóricas da Sociologia e da Análise do Discurso. Foi no processo de instrumentalização de conceitos que os discentes de graduação e de pós-graduação puderam questionar o discurso dominante do colonizador, a partir da contraposição das histórias de vida de pessoas que compunham grupos sociais vulneráveis.

Desse modo, se no espaço acadêmico-científico os estudos publicados propuseram outras narrativas acerca do processo de construção das sociedades na região da Amazônia matogrossense, o que ocorreu a partir das práticas pedagógicas foi a formação universitária de profissionais para intervirem nos espaços públicos e na gestão e implantação das políticas locais. Isso ocorreu porque a Universidade do Estado do Mato Grosso desempenha papel estratégico na formação de recursos humanos na região, em especial nas áreas de educação e engenharias. Não há oferta dos mesmos cursos por outras IES naquela região do Mato Grosso. Assim, os resultados do Programa de Pesquisa em Sociologia acabaram por se dar em duas frentes. Uma, em termos de produção escrita, que se deu limitada aos espaços alcançados por revistas e livros acadêmicos, como é característica desse tipo de publicação. Outra, a formação de profissionais na educação superior, que experienciaram o fazer investigativo por meio de coleta de dados com trabalho de campo e revisão de literatura, e alcançaram a posição de sujeitos, na construção do conhecimento.

\section{A UNIVERSIDADE NA CONSTRUÇÃO DE OUTROS DISCURSOS}

Quando a Universidade do Estado do Mato Grosso se instalou na região amazônica, eram os anos 1990, e a economia local tinha como base a extração da madeira nativa, operando com o desmatamento e comercializando com a região Sudeste e Sul do país. Demandas por formação se restringiam às licenciaturas, o que explica os três primeiros cursos ofertados serem de Pedagogia, Letras e Matemática, no campus aberto no município de Sinop. A dinâmica da economia local foi alterada com o ingresso da agricultura mecanizada a partir de 1996, sobretudo permitida pela tecnologia de sementes de soja e milho de empresas estrangeiras. Daí ao espaço de uma década, as cidades se complexificaram em estratificação social, produção de riquezas e concentração de renda. Os novos desafios fizeram com que a Universidade passasse a oferecer cursos de Engenharia a partir de 2006, primeiro a Civil e, em seguida, a Elétrica.

Também em 2006, a Universidade realizou grande concurso público ${ }^{4}$ para preencher 426 vagas de professor da educação superior, expandindo a presença de docentes concursados com possibilidade de carga horária para pesquisa e extensão. O campus de Sinop recebeu por aquele 4 O edital do concurso com áreas e número de vagas pode ser acessado em:
http://www.unemat.br/concursos/2006/unemat2006/arquivos/edital abertura 8065981.pdf. 
concurso os três primeiros sociólogos, e esses passaram a investigar as dinâmicas sociais locais e regionais (LORD, 2019).

Antes de 2006, havia projetos de pesquisa em curso na Universidade, mas esses eram voltados para processos de ensino-aprendizagem, em função dos cursos oferecidos de licenciatura e dos poucos docentes concursados. Até o concurso de 2006, o quadro docente era composto na relação de um docente efetivo (concursado) para cada quatro docentes temporários (contratados somente para horas-aulas). Assim, o primeiro desafio para que a Universidade fizesse emergir outros discursos sobre as sociedades locais era a limitada existência de profissionais com condições de trabalho para a pesquisa.

Havia um aspecto latente no modo com os trabalhos desenvolvidos no espaço da Universidade interpretavam as dinâmicas locais, em especial o acesso aos bens sociais e ao poder. Era um posicionamento crítico e contrário às propagandas difundidas pelas empresas colonizadoras da região. Com esse posicionamento, e ainda em 2002, foi criado no campus da cidade de Sinop o Grupo de Pesquisa Educação e Estudos de Linguagem (GEdEL), cujo objetivo era compreender os efeitos dos discursos produzidos na Amazônia Legal, nas áreas da educação e linguagem. Nesse Grupo, o projeto de pesquisa Saberes da Terra visava resgatar as narrativas de grupos menos favorecidos acerca da colonização da região. Depois, com o concurso de 2006, ingressaram 61 professores da educação superior neste mesmo campus e o Grupo de Pesquisa ganhou mais força para o desenvolvimento de estudos sobre a realidade local. Os anos seguintes foram decisivos para que as pesquisas avançassem, tanto pela criação dos cursos de Engenharias que introduziram os temas do planejamento urbano e uso e direito ao solo, como pela formação em doutorado dos professores da educação superior, pela política institucional de formação do quadro docente. Em 2011, a criação dos periódicos científicos Revistas Educação, Cultura e Sociedade e Revista Norte@mentos inseriram o grupo docente local em relações nacionais de produção de conhecimento, o que foi solidificado pela abertura dos programas de mestrado profissional e acadêmico em Letras, em 2013 e 2016. Assim se consolidou a produção de conhecimentos pela Universidade do Estado do Mato Grosso na região da Amazônia matogrossense.

\section{A PESQUISA NA UNIVERSIDADE COMO POSSIBILIDADE DE OUTROS DISCURSOS}

A concepção republicana de que as pessoas aprendem durante o processo e por meio do seu envolvimento participativo nas tomadas de decisão (PATEMAN, 1992) tem encontrado espaço nos últimos planejamentos educacionais no Brasil e, recentemente, tornou-se centro da Resolução n. 02/2019 do Conselho Nacional de Educação para a formação de professores nos cursos de licenciatura (BRASIL, 2019). A proposta é que os profissionais formados pela educação superior alcancem as competências para mudar a realidade, em especial a educacional do país. Apesar de não mencionar o termo "empoderamento", as normatizações em termos de currículo têm-se colocado muito perto deste - mesmo que no contexto nacional estejam em curso gestões conservadoras. Em parte, essa ideia republicana já era expressada em teorias marxistas, desde Gramsci (1991) até Freire (FREIRE, SHOR, 1986) ${ }^{5}$. E dada a profundidade e os desdobramentos dessa ideia, hoje mesmo as correntes de pensamento que buscam se distanciar do que foi chamado de pensamento "marxista" acabam por incorporar as ideias de participação e de ator social dali oriundas.

\footnotetext{
5 A depender das escolhas teóricas, essa ideia pode ser identificada desde os textos de Rousseau, como mostra Pateman (1992).
} 
Nesses termos, as atividades investigativas propostas como parte da formação universitária trazem consigo a concepção republicana e, porque é de sua natureza, a busca por realizar-se com a práxis ${ }^{6}$. Com base nisso, os estudos realizados nas disciplinas de Sociologia nos cursos de graduação na Universidade do Estado do Mato Grosso obedeceram a um cronograma de etapas que respeitava os tempos e avanços dos discentes na construção coletiva do projeto investigativo. $\mathrm{O}$ que não podia ser alterado era o campo de pesquisa, restrito aos bairros Jardim do Ouro e Maria Carolina. O motivo da escolha desses bairros pela equipe docente foi por serem as duas únicas áreas que resultaram de um processo de ocupação irregular urbana, no qual nem o poder público, nem os grupos imobiliários conseguiram interferir e evitar na cidade de Sinop. As ocupações resultavam do deslocamento de famílias rurais das cidades mais ao Norte do estado e que empobreciam diante da concentração de terras e poder com o agronegócio em expansão na Amazônia mato-grossense. Os bairros representavam uma ligação entre as cidades maiores e as menores, a contradição de uma região que produz riquezas, mas não democratiza o seu acesso. Os seus moradores traziam como histórico familiar o êxodo rural, o desemprego, a pobreza e o silenciamento diante do discurso dominante sobre a colonização na região por personagens "pioneiros". Os motivos da formação dos dois bairros era, por si, uma contraposição ao senso comum da região e, por isso, compunham um cenário relevante para a pesquisa social que visasse outros discursos.

Após a primeira etapa de aulas teóricas com o estudo de conceitos sociológicos, os discentes elaboravam o primeiro questionário para a entrevista a ser realizada na casa dos moradores, em um dos bairros selecionados. As entrevistas eram realizadas por grupos de três discentes e em quatro etapas, condizentes com quatro momentos de visitas domiciliares aos moradores. O primeiro questionário era geral, rápido, porque composto de cinco questões fechadas de múltipla escolha, e visava a aceitação dos alunos entrevistadores pelos moradores. A relevância do primeiro questionário não estava nos dados coletados e, sim, na possibilidade de estabelecer o diálogo e agendamento de uma próxima visita domiciliar. Esse aspecto do contato e aceitação era importante para os demais momentos da coleta de campo, e tinha como fundamento a ideia de entrada no grupo, como ensina Oliveira (1998). Mas envolvia também a ideia de cidadania e de ética na pesquisa, visto que o morador passava a conhecer a proposta da investigação e escolhia se queria ou não participar das demais etapas. A segunda entrevista com visita era mais demorada, porque usava técnicas de história de vida. A terceira visita era um convite para que o morador caminhasse pelo seu bairro com os discentes e apresentasse o local, as histórias, outros vizinhos e o que mais achasse pertinente. Nessa terceira visita um dos objetivos era registrar imagens do bairro e do morador, algo que também dependia da negociação e aceitação por parte do entrevistado. Com os dados da terceira visita, os discentes elaboravam um artigo como avaliação parcial da disciplina. Após revisado pelos docentes e feitas as alterações pelos discentes, uma cópia do artigo era entregue ao morador na quarta visita, como modo de cumprir com o preceito ético da pesquisa. Comumente, os discentes também entregavam uma fotografia emoldurada daquelas que fizeram com o morador na terceira visita. $E$ as impressões pessoais dos discentes, nessa última visita, compunham o relatório final da disciplina de Sociologia - mais uma atividade avaliativa. Por fim, e como último trabalho da disciplina, os alunos, de modo coletivo, elaboravam exposição fotográfica sobre o bairro, a partir de imagens

\footnotetext{
6 Aqui não cabe a exploração do conceito, mas entende-se por práxis o processo mediante o qual o discente experiencia e reflete sobre sua prática, sendo esta uma etapa fundamental no aprendizado e na percepção acerca da realidade social (FREIRE, 1992). Mais ainda, a práxis é percebida na teoria marxista como meio pelo qual o indivíduo percebe-se como sujeito social, apropriando-se dos instrumentos de luta para a mudança da ordem até então vigente - ou para a mudança nos espaços e práticas escolares, no caso das propostas sobre os cursos de licenciatura.
} 
selecionadas junto aos moradores entrevistados ${ }^{7}$. As exposições fotográficas foram realizadas nos corredores da Universidade, abertas ao público e com convite especialmente feito aos moradores entrevistados. Para muitos dos moradores, essa era a primeira vez que entravam no espaço físico da Universidade, e representava a desmitificação sobre a instituição em dois aspectos: primeiro, porque alterava o imaginário dos moradores sobre a IES; depois, porque colocava em questão o discurso da IES pública de se dizer democrática na atividade de ensino e englobar todos os públicos.

Das etapas da pesquisa acima descrita, cabe dar visibilidade para as fundamentações em termos de processo de ensino-aprendizagem. Isso porque, depois da segunda entrevista, momento em que os discentes percebiam o que era um processo de êxodo rural, eles mesmos respondiam um questionário pessoal contendo, entre outras questões, as seguintes: seu pai ou sua mãe quando criança ou jovem viviam em zonas rurais? Por quais motivos sua família migrou para a cidade? Com tais questionamentos, os discentes comparavam suas respostas pessoais com as dos entrevistados e, basicamente, o que ocorria era uma identificação de histórias familiares. Assim, os discentes compreendiam que eles mesmos eram parte do processo de êxodo rural, que sua geração familiar era urbana como resultado da busca de suas famílias por condições melhores de vida, em comparação ao trabalho e à vida campesina. Desse modo, o processo de investigação constituía um instrumento para o conhecimento do outro que estava sendo visitado no bairro, mas também abria a possibilidade de conhecer a si mesmo e se situar num processo maior e de dimensão nacional da mobilidade humana, das mudanças socioeconômicas e políticas que afetaram as últimas gerações (ZAGO, 2016). Essa compreensão de si como parte de um processo social é condição necessária apontada como objetivo pelas normatizações atuais de formação de profissionais na educação superior (BRASIL, 2019).

\section{RESULTADOS DA PRODUÇÃO DE CONHECIMENTOS NA AMAZÔNIA MATO- GROSSENSE}

As atividades de investigação desenvolvidas no âmbito do Programa de Pesquisa em Sociologia, em especial aquelas atreladas à formação discente, apresentaram resultados que podem ser analisados a partir de três perspectivas: do interesse teórico-metodológico; da formação acadêmica; e do impacto social. A questão do discurso como exercício do poder perpassa as três perspectivas, sobretudo se considerado que os resultados se deram na contracorrente da ordem social estabelecida na região. Cabe aqui, no artigo, explorar aquela mais latente.

Assim, são resultados de interesse teórico-metodológico, aqueles que dialogam com as bases orientadoras da discussão apresentada no artigo, relacionadas ao discurso. Isso porque, como mostrou Foucault (1996), o discurso conta com processos de reprodução e propagação de verdades construídas e que tendem a se desvincular dos fatos reais e reescrever a história, de modo a legitimar o poder e aqueles que o exercem. Também segundo Foucault (2015), o poder e suas formas perpassam as relações cotidianas, gerando proibições. Partindo dessa perspectiva teórica, as atividades de investigação foram buscar espaços, grupos sociais e realidades proibidas e interditadas no discurso dominante, acerca da colonização da Amazônia. A realização das

\footnotetext{
7 Os arquivos das exposições fotográficas visitados para este artigo se referem aos anos de 2014 e 2017. Para as exposições fotográficas foram institucionalizadas propostas de extensão por envolver a comunidade externa, o que reforçou a necessidade de cumprir os preceitos éticos. Internamente ao Curso de Engenharia foi apreciado o plano de ensino e as atividades pelo Colegiado de Curso, registrado nas atas de reuniões disponíveis, publicamente. (http://sinop.unemat.br/site/seoc/).
} 
pesquisas a partir da Universidade revelou modos como opera o poder, ao se utilizar de um discurso homogeneizador que, na prática, não só nega como também silencia discussões sobre o direito de acesso à cidade e suas riquezas. O "fazer" nesse tipo de pesquisa constitui a instrumentalização dos conceitos, ou seja, permite pôr em prática conceitos e análises no momento de observar e buscar compreender a realidade social que circunda os sujeitos. E esse é um avanço, se considerada a relevância que a própria Orlandi (1999) atribuiu à necessidade de materializar a pesquisa e discussão do seu método.

Mas há outro aspecto de interesse teórico-metodológico desenvolvido pelas atividades de pesquisa apresentadas neste artigo. Retomando Foucault (1996), para quem o discurso perpassa as instituições, ordenando as ações que devem se dar em conformidade com o poder, a questão sobre o papel da Universidade é recolocada. Ou seja, a questão sobre a qual o papel da Universidade em sociedades marcadas pelas violências física e simbólica, num primeiro momento, tem como resposta a perpetuação da ordem, ou reprodução das desigualdades, a partir do sistema de ensino - e então reincide a perspectiva de Bourdieu e Passeron (2003). Mas a Sociologia e seus estudos não podem se restringir à aplicação de teorias sem a coleta e análise de dados, menos ainda sem o que Souza (2002) chama de análise de conjuntura ou dos interesses, atores e poderes em disputa. Desse modo, a resposta sobre o papel da Universidade exige que antes se responda outra questão, a de qual motivo levou à implantação dessa instituição na região da Amazônia mato-grossense. Depois, cabe responder sobre como a Universidade percebe sua influência na região, e sobre qual papel ela toma para si naquele contexto. Ora, as perspectivas adotadas e defendidas por seus docentes em pesquisas, extensões e no ensino auxiliam a resposta a tais questões. Como visto, essas são de crítica à ordem estabelecida pelas relações de poder naquela sociedade. E não que a teoria da reprodução esteja equivocada - pelo contrário, já que explica a Universidade ser um local desconhecido pelas populações estudadas -, mas a apropriação que se fez dessa teoria permitiu que outras práticas fossem adotadas justamente para contornar o cenário identificado por Bourdieu.

\section{CONCLUSÕES}

A resposta sobre o papel da Universidade em sociedades marcadas pelas violências física e simbólica, como é o caso da região da Amazônia mato-grossense, não é conclusiva a partir da adoção de uma ou outra perspectiva teórica. Isso porque, como instituição, ela exerce determinado papel social que não se restringe ao de libertar massas populares ou reproduzir desigualdades. Certo é que ela causa impactos, e esses vão depender de fatores internos e externos. O histórico da pesquisa na Universidade do Estado do Mato Grosso, nas cidades da Amazônia mato-grossense, elenca alguns desses fatores, como o efetivo docente, as condições de trabalho, tradições e áreas de pesquisa etc. Já o contexto externo define para ela os temas mais urgentes na agenda de pesquisa, os desafios para o ensino de qualidade, as relações com outros atores etc.

No mesmo sentido, podem ser percebidos os conhecimentos produzidos pela Universidade. Esses serão sempre propostas de verdades, esforços para a construção de discursos que podem se aproximar ou se distanciar do discurso dominante. Mas, dado o histórico dessa instituição no Brasil e da formação das ciências que analisam a sociedade, há uma tendência de posicionamento acadêmico, ideológico, teórico-analítico e político como crítica à ordem social estabelecida, cuja principal característica é a desigualdade de acesso aos direitos e bens sociais. E o tempo que a Universidade ainda tem para se manter nessa posição questionadora depende da sua capacidade de formar novas gerações de profissionais dotados de competências para uma 
análise crítica sobre a sociedade. É nesse espaço de formação de discentes que está o maior poder da instituição em produzir resistências.

\section{REFERÊNCIAS}

BOURDIEU, Pierre. O poder simbólico. Rio de Janeiro: Bertrand, 2007.

BOURDIEU, Pierre; PASSERON, Claude. A reprodução: elementos para uma teoria sobre o sistema de ensino. Petrópolis: Vozes, 2003.

BRASIL. Conselho Nacional de Educação. Resolução n. 2 de 20 de dezembro de 2019. Diário Oficial da República Federativa do Brasil. Poder Executivo. Brasília: 23 de dezembro de 2019, Seção 1, p. 115-119.

CANDIDO, Antônio. Literatura e sociedade. Rio de Janeiro: Ouro sobre azul, 2006.

CARDOSO, Fernando Henrique. Dependência e desenvolvimento na América Latina. Rio de Janeiro: Zahar, 1970.

CELLA-SILVA, Ivone; TOMÉ, Cristinne Leus. Agricultura familiar e desenvolvimento rural: um estudo em três chácaras na cidade de Sinop - Mato Grosso. In: PEREIRA, Alexandre Igor de Azevedo (org.). Agronomia: elo da cadeia produtiva. Ponta Grossa: Atena Editora, 2019.

CHAUI, Marilena. O que é ideologia. São Paulo: Brasiliense, 2004.

FERNANDES, Florestan. Sociedade de classes e subdesenvolvimento. Rio de Janeiro: Zahar, 1972.

FOUCAULT, Michel. A ordem do discurso. São Paulo: Loyola, 1996.

FOUCAULT, Michel. Microfísica do poder. São Paulo: Paz e Terra, 2015.

FREIRE, Paulo. Pedagogia da esperança: um reencontro com a pedagogia do oprimido. Rio de Janeiro: Paz e Terra, 1992.

FREIRE, Paulo; SHOR, Ira. Medo e ousadia: o cotidiano do professor. Rio de Janeiro: Paz e Terra, 1986.

FRODEMAN, Robert; KLEIN, Julie Thompson; PACHECO, Roberto Carlos dos Santos. The Oxford handbook of interdisciplinarity. Oxford: University Press, 2017.

GRAMSCI, Antonio. Maquiavel, a política e o Estado moderno. Rio de Janeiro: Civilização Brasileira, 1991.

GUIMARÃES NETO, Regina Beatriz. A lenda do ouro verde: política de colonização no Brasil contemporâneo. Cuiabá: Unicen, 2002.

LORD, Lucio. Trabalho, educação e cultura: considerações sobre o terceiro movimento de ocupação da Amazônia Mato-Grossense e formação da sociedade local. Revista Educação, Cultura e Sociedade. Sinop/MT, v. 1, n. 2, p. 175-187, jul./dez. 2011.

LORD, Lucio. Qual o papel da Sociologia na formação de professores? Um estudo sobre o curso de Letras na Universidade do Estado do Mato Grosso - Brasil. In: VIII Conferência Internacional Investigação, Práticas e Contextos em Educação, 2019, Leiria - Portugal: Escola Superior de Educação e Ciências Sociais Politécnico de Leiria, v. 1. p. 252-257, 2019.

MARX, Karl; ENGELS, Friedrich. A ideologia alemã. São Paulo: Boitempo, 2007.

OLIVEIRA, Ariovaldo Umbelino de. A fronteira amazônica matogrossense: grilagem, corrupção e violência. Tese de livre-docência. São Paulo, USP, 1997.

OLIVEIRA, Roberto Cardoso de. O trabalho do antropólogo. São Paulo: Unesp, 1998.

ORLANDI, Eni Pulcinelli. Discurso e leitura. São Paulo: Cortez, 1999. 
ORLANDI, Eni Pulcinelli. Análise de discurso: princípios e procedimentos. Campinas: Pontes, 2015.

PATEMAN, Carole. Participação e teoria democrática. Rio de Janeiro: Paz e Terra, 1992.

POPPER, Karl. A lógica da pesquisa científica. São Paulo: Cultrix, 2013.

RIBEIRO, Darcy. O povo brasileiro: a formação e o sentido do Brasil. São Paulo: Companhia das Letras, 2006.

SILVA, Carlos Alberto Franco da; BAMPI, Aumeri Carlos. Regional dynamics of brazilian amazon: between modernization and land conflicts. Cuadernos de Geografía: Revista Colombiana de Geografía, v. 28, p. 340-356, 2019.

SANTOS, Boaventura de Sousa. Um discurso sobre as ciências. Porto: Edições Afrontamento, 1988.

SOUZA, Edison Antônio de. O poder na fronteira: hegemonia, conflitos e cultura no Norte de Mato Grosso. Cuiabá: Ed. UFMT, 2013.

SOUZA, Edison Antônio de; OLIVEIRA, Tânia Pitombo de; STRAUB, Sandra Luzia Wrobel. Sinop: espaço e memória. In: PHILIPPSEN, Neusa; STRAUB, Sandra Luzia Wrobel; OLIVEIRA, Tânia Pitombo de (orgs.). Amazônia: visão caleidoscópica. Recife: Pipa, 2015.

SOUZA, Herbert de. Como se faz análise de conjuntura. Petrópolis: Vozes, 2002.

TOME, Cristinne Léus; ROHDEN, Josiane Brolo. O discurso do progresso e a educação na história de Sinop - Mato Grosso: como é bom alargar fronteiras de nossa pátria!? Revista História da Educação, v. 21, p. 312-334, 2017.

ZAGO, Nadir. Migração rural-urbana, juventude e ensino superior. Revista Brasileira de Educação. Rio de Janeiro, v. 21, n. 64, p. 61-78, mar. 2016.

\section{Informações do autor}

Lucio Jose Dutra Lord

Universidade do Estado do Mato Grosso (UNEMAT)

E-mail: lucio.lord@unemat.br

ORCID: http://orcid.org/0000-0002-7552-3637

Link Lattes: http://lattes.cnpq.br/6372806473090946 